\title{
New small quantum dots for neuroscience (Presentation Video)
}

\section{Paul Selvin}

Paul Selvin, "New small quantum dots for neuroscience (Presentation Video)," Proc. SPIE 8928, Optical Techniques in Neurosurgery, Neurophotonics, and Optogenetics, 89282X (18 March 2014); doi: 10.1117/12.2064194

SPIE. Event: SPIE BiOS, 2014, San Francisco, California, United States 


\title{
New Small Quantum Dots for Neuroscience (Presentation Video)
}

\author{
Paul Selvin, Univ. of Illinois at Urbana-Champaign (United States)
}

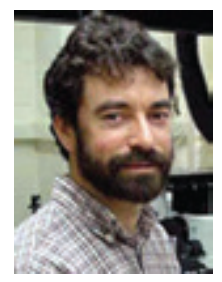

\section{BIOS 2014 Hot Topics Presentation}

In "New Small Quantum Dots for Neuroscience," Paul Selvin (University of Illinois, Urbana-Champaign) notes how the details of synapsis activity in the brain involves chemical receptors that facilitate the creation of the electrical connection between two nerves. In order to understand the details of this neuroscience phenomenon you need to be able to "see" what is happening at the scale of these receptors, which is around 10 nanometers. This is smaller than the diffraction limit of normal microscopy and it takes place on a 3 dimensional structure.

Selvin describes the development of small quantum dots (on the order of 6-9 microns) that are surface-sensitized to interact with the receptors. This allows the application of photo-activated localized microscopy (PALM), a superresolution microscopy that can be scanned through focus to develop a 3D map on a scale that is the same size as the emitter, which in this case are the small quantum dots. The quantum dots are stable in time and provide access to the receptors which allows the imaging of the interactions taking place at the synoptic level.

View presentation video on SPIE's Digital Library: http://dx.doi.org/10.1117/12.2064194 